\title{
Metabolism of Naphthalene by the Cyanobacterium Oscillatoria sp., Strain JCM
}

\author{
By CARL E. CERNIGLIA, ${ }^{1}$ CHASE VAN BAALEN ${ }^{2}$ \\ AND DAVID T. GIBSON ${ }^{1 *}$ \\ ${ }^{1}$ Department of Microbiology, The University of Texas at Austin, \\ Austin, Texas 78712 , U.S.A. \\ ${ }^{2}$ The University of Texas Marine Science Institute, \\ Port Aransas Marine Laboratory, Port Aransas, Texas 78373, U.S.A.
}

(Received 19 April 1979; revised 20 July 1979)

\begin{abstract}
Oscillatoria sp., strain JCM grown photoautotrophically in the presence of naphthalene oxidized the aromatic hydrocarbon to cis-1,2-dihydroxy-1,2-dihydronaphthalene, 4hydroxy-1-tetralone and 1-naphthol. The major metabolite was 1-naphthol. Each product was isolated and shown to have ultraviolet and mass spectra identical to those of authentic compounds. In addition, each metabolite had properties identical to those of authentic compounds when analysed by thin-layer, high-pressure liquid and gas-liquid chromatography. Experiments with $\left[{ }^{14} \mathrm{C}\right]$ naphthalene showed that, over a $24 \mathrm{~h}$ period, the organism oxidized $4.8 \%$ of the added naphthalene. The ratio of organic-soluble to water-soluble metabolites was 41:59. Incubation of whole organisms with naphthalene and ${ }^{18} \mathrm{O}_{2}$ led to the isolation of 1 -naphthol that contained ${ }^{18} \mathrm{O}$. The organism oxidized $1-\left[{ }^{14} \mathrm{C}\right]$ naphthol to 4-hydroxy-1-tetralone. The mechanism of naphthalene oxidation by this cyanobacterium is discussed.
\end{abstract}

\section{INTRODUCTION}

The bacterial oxidation of naphthalene has been studied by several investigators (Walker \& Wiltshire, 1953; Treccani et al., 1954; Davies \& Evans, 1964; Griffiths \& Evans, 1965; Catterall et al., 1971; Jerina et al., 1971; Jeffrey et al., 1975). The initial reaction involves the incorporation of both atoms of an oxygen molecule to form cis-1,2-dihydroxy-1,2dihydronaphthalene (cis-naphthalene dihydrodiol) (Catterall et al., 1971; Jerina et al., 1971; Jeffrey et al., 1975). Subsequent studies have shown that $\mathrm{cis}$-naphthalene dihydrodiol can undergo a pyridine nucleotide-dependent dehydrogenation reaction to yield 1,2dihydroxynaphthalene (Patel \& Gibson, 1974). The latter compound is further oxidized to ring cleavage products (Davies \& Evans, 1964; Dagley, 1971). Recently, it has been shown that fungi oxidize naphthalene to form trans-1,2-dihydroxy-1,2-dihydronaphthalene (trans-naphthalene dihydrodiol) (Ferris et al., 1973; Cerniglia \& Gibson, 1977, 1978; Cerniglia et al., 1978). Oxygen-18 experiments demonstrated that only one atom of molecular oxygen was incorporated into the aromatic nucleus (Ferris et al., 1973). These results are similar to those reported for mammalian enzyme systems (Boyland et al., 1961; Corner \& Young, 1954; Jerina et al., 1968, 1970; Oesch et al., 1972). In view of these different mechanisms for the initial oxidation of the aromatic nucleus by bacteria and fungi, we have initiated a study to determine whether cyanobacteria and microalgae have the capacity to oxidize aromatic hydrocarbons. In an earlier communication, we showed that Agmenellum quadruplicatum, strain PR-6 oxidized naphthalene to 1-naphthol and a compound that was tentatively identified as cis-naphthalene dihydrodiol (Cerniglia et al., 1979). We now report $0022-1287 / 80 / 0000-8717 \$ 02.00$ (C) 1980 SGM 
detailed information on the identity of the products formed from naphthalene by the filamentous cyanobacterium Oscillatoria sp., strain JCM.

\section{METHODS}

Organism. Oscillatoria sp., strain JCM (Morgan, 1975) was maintained in the light on slants of ASP-2 medium (Van Baalen, 1962) containing vitamin $\mathrm{B}_{12}$ at $8 \mu \mathrm{g} \mathrm{1^{-1 }}$.

Photoautotrophic growth conditions. The organism was grown at $39{ }^{\circ} \mathrm{C}$ in Pyrex test tubes $(175 \times 22.5 \mathrm{~mm})$ that contained $20 \mathrm{ml}$ ASP-2 medium. Air enriched with $1 \%(\mathrm{v} / \mathrm{v}) \mathrm{CO}_{2}$ was bubbled through the tubes continuously. Illumination was provided by two F48T12/CW/HO fluorescent lamps (General Electric, Cleveland, Ohio, U.S.A.). The lamps were placed on each side of the water bath at a distance of $8.5 \mathrm{~cm}$ from the growth tube. The procedure is an adaptation of the method described by Myers (1950).

Metabolic experiments. Organisms grown as described above were transferred during exponential growth to a closed growth system, consisting of a Bellco Glass $600 \mathrm{ml}$ Nepheloculture flask (no. 2574) with a $22 \times 175 \mathrm{~mm}$ side-arm and screw-cap closures. The top seal was a $1 \mathrm{mil}(0 \cdot 001 \mathrm{in})$ Teflon membrane covered with acetone-rinsed aluminium foil and a plastic cap. The small side-arm was sealed with a plastic cap with a no. 60 drill hole in the centre. The cap was lined with a septum (Hamilton no. 760-18) and a layer of aluminium foil and a 1 mil Teflon membrane.

In a typical experiment, $30 \mathrm{ml}$ exponentially growing culture (about $0.8 \mathrm{mg}$ dry wt $\mathrm{ml}^{-1}$ ) was transferred directly from the growth tube to a sterile flask. Naphthalene $(0.3 \mathrm{mg}$ in $0.1 \mathrm{ml} 95 \%$ ethanol) was added to the culture medium and the flask was sealed. Ethanol had no effect on growth. The flask was clamped to the top of a linear rotating bar with a $5 \mathrm{~cm}$ throw and shaken at $40 \mathrm{rev}$. min. ${ }^{-1}$ The bottom 3 to $4 \mathrm{~cm}$ of the flask was immersed in a $30^{\circ} \mathrm{C}$ water bath. The culture was equilibrated for $15 \mathrm{~min}$ in the dark during which time $\mathrm{CO}_{2}$ was added via a syringe through the small side-arm. The $\mathrm{CO}_{2}$ concentration in the flask was maintained between 0.5 and $1.0 \%$ throughout the experiment. Illumination was provided by two fluorescent lamps (F48T12/CW/HO) positioned $29 \mathrm{~cm}$ below the water bath. Dark experiments were conducted as described above except that the flasks were carefully covered with two layers of aluminium foil. In control experiments, naphthalene was incubated in ASP-2 medium in the absence of micro-organisms and also in the presence of heat-killed organisms.

Experiments with $\left[1{ }^{14} \mathrm{C}\right]$ naphthalene $[440 \mathrm{nmol}, 0.88 \mu \mathrm{Ci}(33 \mathrm{kBq})]$ and $1-\left[1-{ }^{14} \mathrm{C}\right] \mathrm{naphthol}[417 \mathrm{nmol}$, $8 \cdot 38 \mu \mathrm{Ci}(310 \mathrm{kBq})]$ were conducted as described above.

Extraction and detection of metabolic products. After $24 \mathrm{~h}$ incubation, organisms were removed by filtration through cheesecloth and the filtrate was extracted with three equal volumes of ethyl acetate. The organic extract was dried over anhydrous $\mathrm{Na}_{2} \mathrm{SO}_{4}$ and the solvent was removed in vacuo. Preliminary analysis of the resulting brown oil was conducted by thin-layer, high-pressure liquid and gas-liquid chromatography.

Analytical methods. Absorption spectra were determined on a Beckman model 25 recording spectrophotometer. Analytical thin-layer chromatography was performed with Polygram Sil G/UV $\mathrm{Us4}_{\mathbf{2}}$ plastic sheets (Machery-Nagel \& Co., Duren, Germany). For preparative thin-layer chromatography, glass plates coated with silica gel $60 \mathrm{~F}_{254}$ (E. Merck, Darmstadt, Germany) were used. The solvent used for chromatography was chloroform/acetone $(8: 2, \mathrm{v} / \mathrm{v})$. Naphthalene metabolites were located on chromatograms by viewing under ultraviolet light and also by spraying with Gibb's reagent [2,6-dichloroquinone-4-chloroimide in methanol $(2 \%, \mathrm{w} / \mathrm{v})]$. Multiple development of the chromatogram was necessary in order to achieve separation of the cis- and trans-isomers of naphthalene dihydrodiol. The $R_{F}$ values for these compounds after three developments were 0.23 and $0 \cdot 17$, respectively.

Radioactive metabolites were co-chromatographed with authentic samples of 1-naphthol, 4-hydroxy-1tetralone, cis-naphthalene dihydrodiol and trans-naphthalene dihydrodiol. The conditions used for chromatography were as described above. Labelled metabolites were detected by autoradiography with Kodak X-ray film (blue-sensitive SB-54). Radioactive zones on the chromatogram were cut out and quantified by liquid scintillation spectrometry.

A Finnegan model 3100 mass spectrometer coupled to a gas chromatograph and model 6000 computer system was used to identify metabolites. A glass column $(2 \mathrm{~m} \times 1.5 \mathrm{~mm}$ i.d.) packed with $3 \% \mathrm{OV}-1$ on Chromosorb $\mathrm{W}$ was used with the following operating conditions: injection temperature, $220^{\circ} \mathrm{C}$; programme, 100 to $250^{\circ} \mathrm{C}$ at $8{ }^{\circ} \mathrm{C} \mathrm{min}^{-1}$; flow rate of carrier gas (helium), $30 \mathrm{ml} \mathrm{min}^{-1}$. The following conditions were used for mass spectrometry: molecular separator temperature, $350^{\circ} \mathrm{C}$; ion source temperature, $100{ }^{\circ} \mathrm{C}$; ionization beam, $70 \mathrm{eV}$; ionization current, $200 \mu \mathrm{A}$.

High-pressure liquid chromatography (h.p.l.c.) was used to separate and quantify the naphthalene metabolites. The component system used consisted of a Waters Associate model 6000A solvent delivery system, model U-6K septumless injector and model 440 absorbance detector operated at $254 \mathrm{~nm}$ or $280 \mathrm{~nm}$. 
A $\mu$ Bondapak $\mathrm{C}_{18}$ column $(3.9 \mathrm{~mm} \times 30 \mathrm{~cm}$ ) was used for the separation of polar metabolites, which was achieved with a programmed methanol/water gradient (50 to $95 \%$, v/v; $30 \mathrm{~min}$ ). To resolve 1-naphthol and 2-naphthol, a $\mu$ Porasil column $(3.9 \mathrm{~mm} \times 30 \mathrm{~cm})$ was used with hexane/ethyl acetate $(9: 1, \mathrm{v} / \mathrm{v})$ as solvent and a flow rate of $1.5 \mathrm{ml} \mathrm{min}-1$. This system was run isocratically for $15 \mathrm{~min}$. Fractions of $0.75 \mathrm{ml}$ were collected and the radioactivity present in each fraction was determined with a Beckman LS-250 liquid scintillation counter, using Aquasol-2 (New England Nuclear) as the scintillation fluid.

Oxygen-18 incorporation experiment. A suspension $(30 \mathrm{ml})$ of Oscillatoria was placed in a modified Bellco Glass $600 \mathrm{ml}$ Nepheloculture flask with a vacuum outlet at its top and the neck of the ${ }^{18} \mathrm{O}_{2}$ bulb was fused to the side of the flask. The culture flask was alternately flushed with $\mathrm{N}_{2}$ and evacuated and then $100 \mathrm{ml}$ ${ }^{18} \mathrm{O}_{2}(99 \%$ enriched) was introduced into the flask. The isotopic composition of the oxygen portion of the atmosphere at the beginning of the experiment was $55 \%{ }^{16} \mathrm{O}{ }^{16} \mathrm{O}, 4 \%{ }^{16} \mathrm{O}-{ }^{18} \mathrm{O}, 41 \%{ }^{18} \mathrm{O}-{ }^{18} \mathrm{O}$ as measured by mass spectrometry. After incubation under the conditions described above, $0.3 \mathrm{mg}$ naphthalene was added in $0.1 \mathrm{ml} 95 \%$ ethanol. 1-Naphthol was isolated by h.p.l.c. and its isotopic abundance was determined using the Finnegan mass spectrometer. The isotopic abundance was calculated from the relative intensities of the molecular ions of the ${ }^{16} \mathrm{O}$ and ${ }^{18} \mathrm{O}$ species at $m / e 144$ and 146 , respectively.

Chemicals. Naphthalene (99.95\%) was from Aldrich Chemical Co., Milwaukee, Wis., U.S.A. [1-14C]Naphthalene [2 mCi mmol-1 $\left.\left(74 \mathrm{MBq} \mathrm{mmol}^{-1}\right)\right]$ and 1-[1-14 C]naphthol [20.1 $\left.\mathrm{mCi} \mathrm{mmol}^{-1}\left(744 \mathrm{MBq} \mathrm{mmol}^{-1}\right)\right]$ were from Amersham/Searle, Arlington Heights, Ill., U.S.A.trans-Naphthalene dihydrodiol was a generous gift from L. A. Kapicak, Union Carbide Corp., Charleston, W.V., U.S.A. cis-Naphthalene dihydrodiol was prepared as described previously (Jeffrey et al., 1975). Other naphthalene derivatives were purified as described previously (Cerniglia \& Gibson, 1977). Solvents for h.p.l.c. were purchased from Burdick and Jackson Laboratories, Muskegon, Mich., U.S.A. ${ }^{18} \mathrm{O}_{2}(99 \%$ enriched) was from Stohler Isotope Co., Rutherford, N.J., U.S.A.

\section{RESULTS}

\section{Preliminary investigations}

Oscillatoria sp., strain JCM was grown photoautotrophically in the presence of naphthalene. After $24 \mathrm{~h}$, the cells were filtered and the culture filtrate was extracted with ethyl acetate. Initial thin-layer chromatographic analysis of the ethyl acetate extracts in chloroform/acetone $(8: 2, \mathrm{v} / \mathrm{v})$ showed the presence of a u.v.-absorbing compound which had a similar $R_{F}$ value $(0 \cdot 69)$ to 1 -naphthol. This metabolite and authentic 1-naphthol both gave a blue colour when sprayed with Gibb's reagent after exposure to ammonia vapour. When the experiment was repeated with $\left[{ }^{14} \mathrm{C}\right]$ naphthalene, autoradiographic analysis revealed the presence of at least six compounds (Fig. 1). Each of the radioactive regions was cut out of the thin-layer chromatography plate and the radioactivity in each fraction was measured (Table 1). Most of the radioactivity $(69 \%)$ was observed in the region designated as $\mathrm{M}-2$ (Fig. 1). Compound M-2 co-chromatographed with authentic 1-naphthol.

The ethyl acetate extract obtained after incubating organisms with $\left[{ }^{14} \mathrm{C}\right]$ naphthalene was also analysed by h.p.l.c. The elution profile is compared with that for several authentic naphthalene derivatives in Fig. 2. The results clearly implicate 1-naphthol as the major metabolite and suggest the possible formation of small amounts of cis-naphthalene dihydrodiol.

\section{Isolation and identification of naphthalene metabolites}

Large-scale metabolic experiments were conducted in order to obtain sufficient material for the isolation and identification of each naphthalene metabolite. Preparative thin-layer chromatography of the ethyl acetate-soluble residue gave similar results to those shown in Fig. 1. Each of the areas of silica gel was removed and extracted with methanol. Extracts from several chromatograms were pooled in order to obtain sufficient material for further purification by h.p.l.c.

H.p.l.c. analysis of the region designated $M-2$ revealed the presence of a major product with an identical retention time to that of 1-naphthol (Fig. $3 a, b$ ). The absorption spectra of this metabolite and 1-naphthol were identical (Fig. $3 \mathrm{c}$ ). In addition, the mass spectrum of the metabolite showed an intense molecular ion at $m / e 144$ and a fragmentation pattern identical to that given by 1-naphthol. As can be seen in Fig. 3(b), a minor product was also 


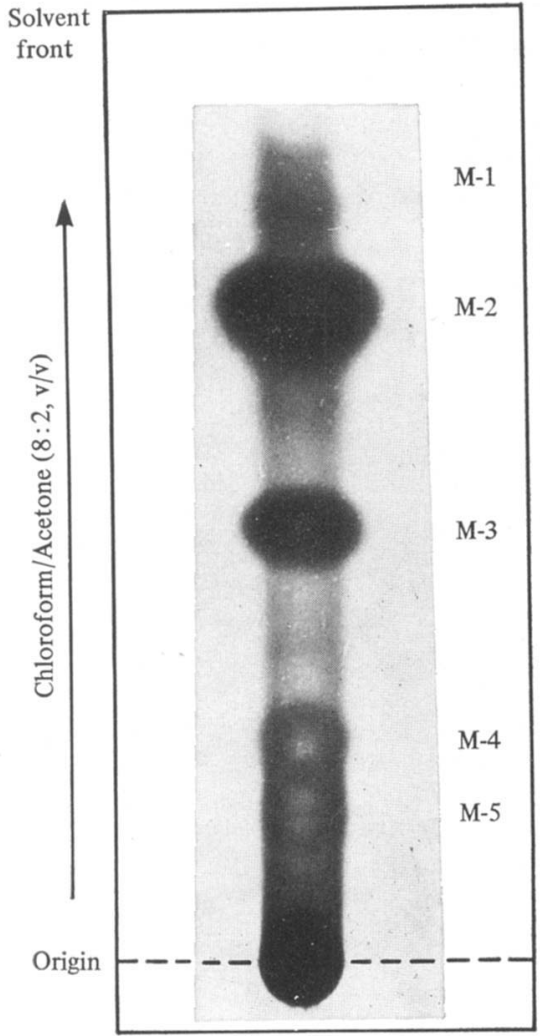

Fig. 1

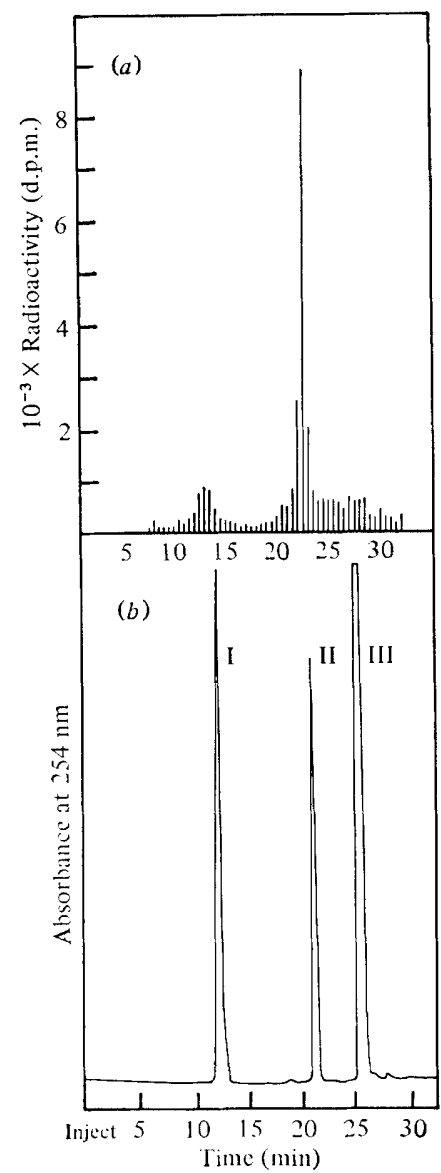

Fig. 2

Fig. 1. Autoradiogram of metabolites formed from $\left[1-{ }^{14} \mathrm{C}\right]$ naphthalene by Oscillatoria sp., strain JCM. Procedures were as described in Methods. Areas on the thin-layer chromatogram that contained radioactivity were arbitrarily designated M-1 to M-5.

Fig. 2. Separation of naphthalene metabolites by h.p.l.c. (a) Radioactive metabolites formed from $\left[1-{ }^{14} \mathrm{C}\right]$ naphthalene by Oscillatoria sp., strain JCM. Fractions eluting from the chromatograph were collected at $\mathbf{0 . 5}$ min intervals and their radioactivity was measured as described in Methods. (b) Authentic naphthalene derivatives: cis-naphthalene dihydrodiol (I), 1-naphthol (II) and naphthalene (III) were detected by absorbance at $254 \mathrm{~nm}$.

H.p.l.c. conditions were as described in Methods. It was not possible to chromatograph the radioactive extract and reference compounds simultaneously due to the large amount of $254 \mathrm{~nm}$ absorbing material produced by Oscillatoria sp., strain JCM.

detected by h.p.l.c. This compound had an identical retention time to 2-naphthol. However, insufficient material was available for further structural identification.

The chromatographic properties of compound M-3 were identical to those of 4-hydroxy1-tetralone $\left(R_{F} 0 \cdot 44\right)$. The ultraviolet absorption spectrum of compound M-3 was similar to that of 4-hydroxy-1-tetralone (Fig. 4). In addition, when analysed by gas chromatography/mass spectrometry the metabolite product showed a retention time $(4 \cdot 3 \mathrm{~min})$ and mass fragmentation pattern $(\mathrm{m} / \mathrm{e} 162)$ identical to those given by 4-hydroxy-1-tetralone. These properties of compound M-3 are in close agreement with those reported for 4hydroxy-1-tetralone formed during the fungal oxidation of naphthalene (Cerniglia \& Gibson, 1977; Cerniglia et al., 1978) and the bacterial oxidation product formed from 1naphthol (Bollag et al., 1975). 
Table 1. Distribution of radioactivity in the metabolites formed from $\left[1-{ }^{14} \mathrm{C}\right]$ naphthalene by Oscillatoria sp., strain JCM

The radioactive areas of the thin-layer chromatogram that were detected by autoradiography (Fig. 1) were removed and counted as described in Methods.

$\begin{array}{ccc}\text { Metabolite } & \begin{array}{c}\text { Padioactivity } \\ \text { (d.p.m.) }\end{array} & \begin{array}{c}\text { Percentage } \\ \text { of total } \\ \text { radioactivity } \\ \text { recovered }\end{array} \\ \text { M-1 } & 240 & 0 \cdot 6 \\ \text { M-2 } & 28780 & 69 \cdot 5 \\ \text { M-3 } & 3480 & 8 \cdot 4 \\ \text { M-4 } & 690 & 1 \cdot 7 \\ \text { M-5 } & 1980 & 4 \cdot 8 \\ \text { Origin } & 6240 & 15 \cdot 0\end{array}$
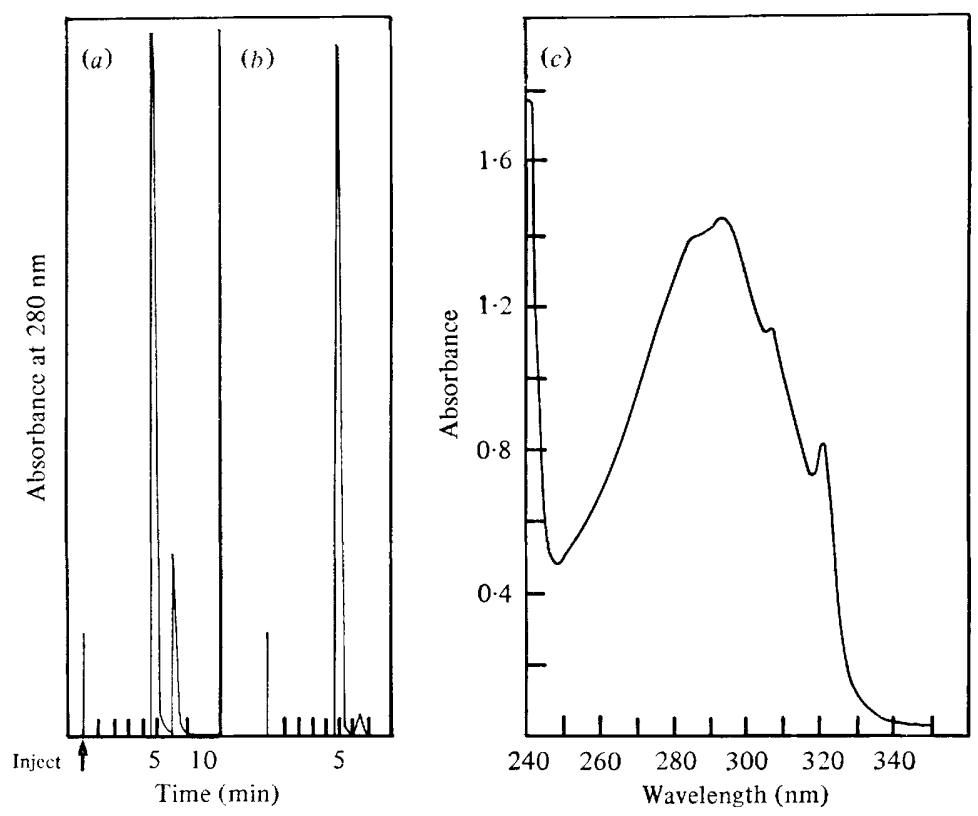

Fig. 3. Separation and spectral properties of the major component in the area designated M-2 (Fig. 1). (a) Separation of synthetic 1- and 2-naphthol by h.p.1.c. (b) Resolution of components present in the M-2 region by h.p.l.c. (c) Absorbance spectrum of the major product in fraction M-2 after purification by h.p.l.c. H.p.l.c. conditions were as described in Methods.

Compound M-4 co-chromatographed with cis-naphthalene dihydrodiol. As described in Methods, multiple development in chloroform/acetone $(8: 2, \mathrm{v} / \mathrm{v})$ separates cis-naphthalene dihydrodiol from the trans-isomer. When compound M-4 was analysed by h.p.l.c. its retention time was identical to that of authentic cis-naphthalene dihydrodiol $(12.5 \mathrm{~min})$. The absorption spectrum of the product formed by acid-treatment was identical to that given by 1-naphthol (Fig. 5). These observations suggest that compound M-4 is cisnaphthalene dihydrodiol. Further support for a cis relative stereochemistry in compound M-4 was provided by comparing its rate of acid-catalysed dehydration with the rates obtained with authentic cis- and trans-naphthalene dihydrodiol. The rate of dehydration of compound M-4 was similar to that of $c i s$-naphthalene dihydrodiol.

Compound M-5 had thin-layer chromatographic properties similar to those observed for trans-naphthalene dihydrodiol. However, when analysed by h.p.l.c. several products were detected. Synthetic trans-naphthalene dihydrodiol did not co-chromatograph with any of 


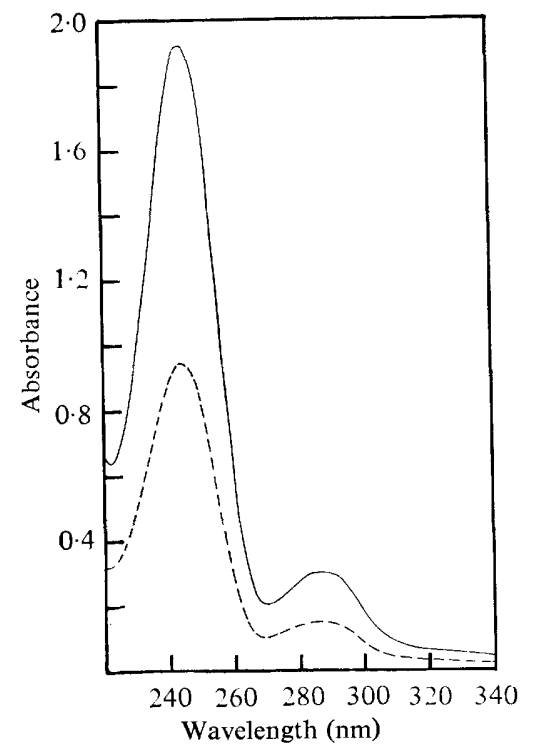

Fig. 4

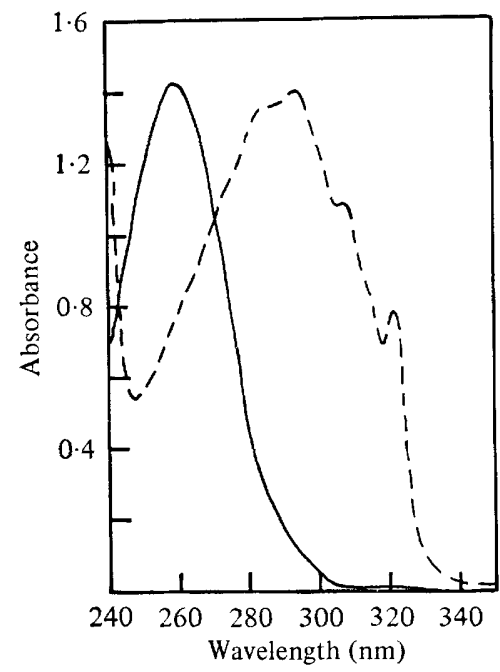

Fig. 5

Fig. 4. Absorption spectra of the metabolite isolated from the M-3 region of the preparative thinlayer chromatogram (-) and authentic 4-hydroxy-1-tetralone (-- ${ }_{-}$). Each compound was dissolved in methanol and the spectra were recorded on a Beckman model 25 recording spectrophotometer.

Fig. 5. Absorption spectra of compound M-4 after purification by h.p.l.c., using a $\mu$ Bondapak $\mathrm{C}_{18}$ column as described in Methods. Spectra were recorded on a Beckman model 25 recording spectrophotometer before (-) and after $(---)$ acidification with $0 \cdot 1 \mathrm{ml} 2 \cdot 5 \mathrm{M}_{-} \mathrm{H}_{2} \mathrm{SO}_{4}$.

the compounds detected by h.p.l.c. We have been unable to obtain sufficient amounts of compound M-5 to provide structural information.

Fungi (Cerniglia \& Gibson, 1977; Cerniglia et al., 1978) and bacteria (Bollag et al., 1975) are known to oxidize 1-naphthol to 4-hydroxy-1-tetralone. To investigate the possibility that 1-naphthol was the precursor of the 4-hydroxy-1-tetralone formed from naphthalene by Oscillatoria sp., strain JCM, cells were incubated with $1-\left[{ }^{14} \mathrm{C}\right]$ naphthol as described in Methods. Subsequent autoradiographic analysis revealed the presence of a radioactive metabolite that co-chromatographed with 4-hydroxy-1-tetralone. In addition, a second product was formed whose chromatographic properties were identical to those shown for compound M-5 in Fig. 1. The 1-[14 C]naphthol used in this experiment was purified by h.p.l.c. prior to use. However, under the experimental conditions employed 1-naphthol was subject to non-enzymic oxidation. Autoradiograms prepared from flasks that had been incubated with $1-\left[{ }^{4} \mathrm{C}\right]$ naphthol in the presence of heat-killed Oscillatoria sp., strain JCM indicated the presence of two radioactive products that were less polar than 1-naphthol. These compounds had identical chromatographic properties to those in the region designated $M-1$ in Fig. 1. The control experiment did not reveal the presence of any compounds with $R_{F}$ values lower than that observed for 1-naphthol.

Table 1 shows that $15 \%$ of the recovered radioactivity was accounted for as polar products (origin, Fig. 1). No further attempt has been made to identify these metabolites which could be conjugated and/or polyhydroxylated products. Water-soluble products are also formed from naphthalene by Oscillatoria sp., strain JCM. Approximately $4.8 \%$ of the added naphthalene was metabolized. The ratio of ethyl acetate-soluble metabolites to water-soluble metabolites was $41: 59$. The nature of the water-soluble products remains to be determined. 


\section{Oxygen-18 incorporation studies}

The mass spectra of 1-naphthol formed in the presence of ${ }^{16} \mathrm{O}_{2}$ and also ${ }^{18} \mathrm{O}_{2}$ were determined. The 1-naphthol formed in the presence of ${ }^{16} \mathrm{O}_{2}$ showed a parent peak at $m / e 144$. The 1-naphthol produced in the presence of ${ }^{18} \mathrm{O}_{2}$ showed an increase in the peak at $\mathrm{m} / e 146$ indicating the incorporation of ${ }^{18} \mathrm{O}_{2}$ into naphthalene to form 1-naphthol. Approximately $57 \%$ incorporation of $\mathrm{O}_{2}$ into 1-naphthol was observed.

\section{DISCUSSION}

Previous studies on the effect of naphthalene on cyanobacteria have focused on its toxicity and its effects on growth and photosynthesis (Gordon \& Prouse, 1973; Pulich et al., 1974; Soto et al., 1975a, b; Winters et al., 1976; Kusk, 1978). It has not been established whether the detrimental effects of naphthalene on these organisms are due to the substrate itself or to one of its metabolites. There is ample evidence from studies with higher organisms that the toxic and, in some cases, carcinogenic effects of aromatic hydrocarbons are caused by metabolic products formed from the parent compound (Miller \& Miller, 1974). The present investigation demonstrates that a cyanobacterium, Oscillatoria sp., strain JCM, converts naphthalene to several metabolites; this ability is not unique to this organism or to this algal group. In the following paper (Cerniglia et al., 1980), we demonstrate that a wide variety of cyanobacteria, several green algae, red algae and diatoms, and a brown alga will metabolize this aromatic hydrocarbon. Under the experimental conditions used to investigate naphthalene metabolism by Oscillatoria sp., strain JCM, naphthalene was not toxic and did not show any effect on growth or photosynthesis.

The predominant metabolite formed from naphthalene was conclusively identified as 1naphthol. When organisms were incubated with naphthalene in the dark no metabolic products were detected. The same results were obtained when heat-inactivated cells were incubated with naphthalene in the light. Experiments with ${ }^{18} \mathrm{O}_{2}$ showed that $57 \%$ of the 1-naphthol formed involved the incorporation of molecular oxygen. Although these results could implicate the initial formation of naphthalene 1,2-oxide, as has been reported for the mammalian (Jerina et al., 1970) and fungal (Ferris et al., 1973; Cerniglia \& Gibson, 1977, 1978; Cerniglia et al., 1978) oxidation of naphthalene, it is clear that alternative mechanisms for 1-naphthol formation exist in Oscillatoria sp., strain JCM. Thus, at this time we cannot definitely state that the organism oxidizes naphthalene via naphthalene 1,2-oxide. If this reaction does occur one might expect to isolate trans-naphthalene dihydrodiol as a metabolite since heterotrophic eukaryotic organisms contain the enzyme epoxide hydratase which catalyses the trans addition of water to arene oxides (Oesch et al., 1972). Instead of trans-naphthalene dihydrodiol, Oscillatoria sp., strain JCM formed the cis-isomer which has been identified as a naphthalene metabolite formed by bacteria (Catterall et al., 1971; Jeffrey et al., 1975). Only small amounts of $c i s$-naphthalene dihydrodiol were isolated and evidence for a cis relative stereochemistry was obtained from its chromatographic properties and by comparing its rate of acid-catalysed dehydration with the rates observed with authentic samples of cis- and trans-naphthalene dihydrodiol. Jerina et al. (1976) have shown that rates of dehydration are reasonably reliable for the assignment of relative stereochemistry since cis-arene dihydrodiols are dehydrated much faster than the corresponding trans-isomers. Rigorous stereochemical analysis remains to be completed in order to assign the absolute stereochemistry of the metabolite. As mentioned above, cis-naphthalene dihydrodiol is readily dehydrated to yield 1-naphthol. Consequently, the incubation (pH 8 or above) and isolation procedures (neutral extraction) used in the present investigation were carried out under conditions that would not lead to the formation of 1-naphthol from cis-naphthalene dihydrodiol.

A third metabolite formed from naphthalene by Oscillatoria sp., strain JCM, was 


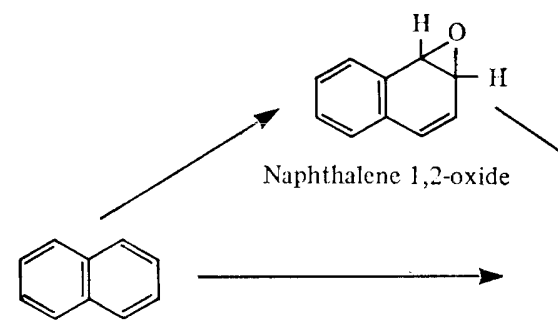

Naphthalene

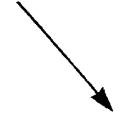

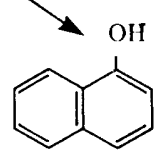

1-Naphthol

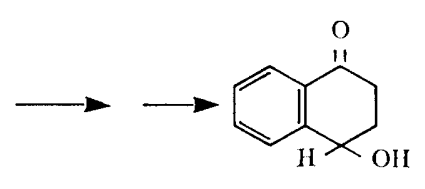

4-11ydroxy-1-tetralone

Further metabolism

cis-Naphthalene dihyclrodiol

Fig. 6. Proposed pathways for the metabolism of naphthalene by Oscillatoria sp., strain JCM.

4-hydroxy-1-tetralone. Autoradiographic studies with 1-[14C]naphthol showed that the tetralone was formed by the further metabolism of 1-naphthol. These results are similar to those reported for the bacterial (Bollag et al., 1975) and fungal (Cerniglia \& Gibson, 1977) oxidation of 1-naphthol.

Oscillatoria sp., strain JCM did not catalyse extensive metabolism of naphthalene $(4 \cdot 8 \%)$, a feature that has made it difficult to isolate and identify all of the reaction products. Thus, in $24 \mathrm{~h}$, only $2.0 \%$ of the added naphthalene could be accounted for as ethyl acetate-soluble metabolites. A somewhat higher percentage $(2.8 \%)$ of water-soluble product(s) was detected in the culture medium after extraction with ethyl acetate. This result suggests the formation of ring cleavage products and/or conjugated metabolites. Ellis (1977) has demonstrated that freshwater algae form ${ }^{14} \mathrm{CO}_{2}$ when they are grown in the presence of $\left[{ }^{14} \mathrm{C}\right]$ phenol or $\left[{ }^{14} \mathrm{C}\right]$ catechol, an observation which suggests that algae may have the enzymic capacity to catalyse fission of the aromatic nucleus.

Our results suggest that Oscillatoria sp., strain JCM may possess several mechanisms for initiating the oxidation of naphthalene. Three possible pathways are shown in Fig. 6 . A monooxygenase could form naphthalene 1,2-oxide which would yield 1-naphthol after isomerization. This pathway has been well documented for heterotrophic eukaryotic organisms (Jerina et al., 1970; Oesch et al., 1971, 1972). The formation of cis-naphthalene dihydrodiol could be explained by a dioxygenase reaction which has been demonstrated to occur in the bacterial oxidation of naphthalene (Catterall et al., 1971; Jerina et al., 1971; Jeffrey et al., 1975). An alternative mechanism for the formation of 1-naphthol may be a light-dependent direct hydroxylation of the aromatic nucleus. Clearly further studies are required to elucidate the mechanism of hydroxylation and the precise role of the enzymes involved in the metabolism of naphthalene.

This investigation was supported by grant no. ES-00537 awarded by the National Institute of Environmental Health Sciences, D.H.E.W. C.E.C. is a postdoctoral trainee supported by grant no. T32 CA09182 awarded by the National Cancer Institute, D.H.E.W. We thank Rita O'Donnell and Joseph C. Morgan for technical assistance, Dr Ken Winters for his help in the oxygen-18 experiments and Roberta De Angelis for assistance in preparing the manuscript. 


\section{REFERENCES}

Bollag, J. M., Czaplicki, E. J. \& Minard, R. D. (1975). Bacterial metabolism of 1-naphthol. Agricultural and Food Chemistry 23, 85-90.

Boyland, E., Ramsay, G. S. \& Sims, P. (1961). Metabolism of polycyclic compounds. 18. The secretion of metabolites of naphthalene, 1,2dihydroxynaphthalene and 1,2-epoxy-1,2,3,4tetrahydronaphthalene in rat bile. Biochemical Journal 78, 376-384.

Catterall, F. A., Murray, K. \& Williams, P. A. (1971). The configuration of the 1,2-dihydroxy1,2-dihydronaphthalene formed in the bacterial metabolism of naphthalene. Biochimica et biophysica acta 237, 361-364.

Cerniglia, C. E. \& Gibson, D. T. (1977). Metabolism of naphthalene by Cunninghamella elegans. Applied and Environmental Microbiology 34, 363370.

Cerniglia, C. E. \& Gibson, D. T. (1978). Metabolism of naphthalene by cell extracts of Cunninghamella elegans. Archives of Biochemistry and Biophysics 186, 121-127.

Cerniglia, C. E., Hebert, R. L., Szaniszlo, P. J. \& Gibson, D. T. (1978). Fungal transformation of naphthalene. Archives of Microbiology 117, 135 143.

Cerniglia, C. E., Gibson, D. T. \& Van BaAlen, C. (1979). Algal oxidation of aromatic hydrocarbons: formation of 1-naphthol from naphthalene by Agmenellum quadruplicatum, strain PR-6. Biochemical and Biophysical Research Communications $88,50-58$.

Cerniglia, C. E., Gibson, D. T. \& Van BaAlen, C. (1980). Oxidation of naphthalene by cyanobacteria and microalgae. Journal of General Microbiology 116, 495-500.

Corner, E. D. S. \& Young, L. (1954). Biochemical studies of toxic agents. 7. The metabolism of naphthalene in animals of different species. Biochemical Journal 58, 647-655.

DAGLEY, S. (1971). Catabolism of aromatic compounds by microorganisms. Advances in Microbial Physiology 6, 1-46.

Davies, J. I. \& Evans, W. C. (1964). Oxidative metabolism of naphthalene by soil pseudomonads. Biochemical Journal 91, 251-261.

ELLIS, B. E. (1977). Degradation of phenolic compounds by fresh-water algae. Plant Science Letters 8, 213-216.

Ferris, J. P., Fasco, M. J., Stylianopoulou, F. L., Jerina, D. M., Daly, J. W. \& JefFrey, A. M. (1973). Mono-oxygenase activity in Cunninghamella bainieri: evidence for a fungal system similar to liver microsomes. Archives of Biochemistry and Biophysics 156, 97-103.

Gordon, D. C. \& Prouse, N. J. (1973). The effects of three oils on marine phytoplankton photosynthesis. Marine Biology 22, 329-333.

Grifriths, E. \& Evans, W. C. (1965). A cell-free perhydroxylase system from soil pseudomonads. Biochemical Journal 95, 51.

JefFrey, A. M., YeH, H. J. C., Jerina, D. M., Patel, T. R., DaveY, J. F. \& Gibson, D. T. (1975). Initial reactions in the oxidation of naph- thalene by Pseudomonas putida. Biochemistry 14 575-584.

Jerina, D. M., Daly, J. W., Witkop, B., ZaltzmanNirenberG, P. \& Udenfriend, S. (1968). The role of arene oxide-oxepin systems in the metabolism of aromatic substrates. III. Formation of 1,2naphthalene oxide from naphthalene by liver microsomes. Journal of the American Chemical Society 90, 6525-6527.

Jerina, D. M., Daly, J. W., WitkoP, B., ZaltzMaNNirenberG, P. \& Udenfriend, S. (1970). 1,2Naphthalene oxide as an intermediate in the microsomal hydroxylation of naphthalene. Biochemistry 9, 147-156.

Jerina, D. M., Daly, J. W., JefFrey, A. M. \& GiBson, D. T. (1971). cis-1,2-Dihydroxy-1,2-dihydronaphthalene: a bacterial metabolite from naphthalene. Archives of Biochemistry and Biophysics 142, 394-396.

Jerina, D. M., Selander, H., YaGi, H., Wells, M. C., Davey, J. F., Mahadevan, V. \& Gibson, D. T. (1976). Dihydrodiols from anthracene and phenanthrene. Journal of the American Chemical Society 98, 5988-5996.

KusK, K. O. (1978). Effects of crude oil and aromatic hydrocarbons on the photosynthesis of the diatom Nitzschia. Physiologia plantarum 43, 1-6.

Miller, E. C. \& Miller, J. A. (1974). Biochemical mechanisms of chemical carcinogenesis. In Molecular Biology of Cancer, pp. 377-402. Edited by H. Bush. New York: Academic Press.

Morgan, J. C. (1975). Studies of the diatoms of the Northwestern Gulf of Mexico: identification, distribution and cultural studies. Master's thesis, University of Texas at Austin, Austin, Texas, U.S.A.

MYERS, J. (1950). The culturing of algae for physiological research. In The Culturing of Algae, pp. 45-51. Edited by J. Brunel, G. W. Prescott \& L. H. Tiffany. Yellow Springs, Ohio, U.S.A.: Charles F. Kettering Foundation.

Oesch, F., Jerina, D. M. \& Daly, J. W. (1971). Conversion of naphthalene to trans-naphthalene dihydrodiol: evidence for the presence of a coupled aryl monooxygenase-epoxide hydrase system in hepatic microsomes. Biochemical and Biophysical Research Communications 46, 1713-1720.

Oesch, F., Jerina, D. M., Daly, J. W., Lu, A. Y. H., Kuntzman, R. \& Conney, A. J. (1972). A reconstituted microsomal enzyme system that converts naphthalene to trans-1,2-dihydroxy-1,2dihydronaphthalene via naphthalene-1,2-oxide. Presence of epoxide hydrase in cytochrome $P-450$ and $P$-448 fractions. Archives of Biochemistry and Biophysics 153, 62-67.

Patel, T. R. \& Gibson, D. T. (1974). Purification and properties of $(+)$-cis-naphthalene dihydrodiol dehydrogenase of Pseudomonas putida. Journal of Bacteriology, 119, 879-888.

Pulich, W. M., JR, Winters, K. \& Van BaAlen, C. (1974). The effects of No. 2 fuel oil and two crude oils on the growth and photosynthesis of microalgae. Marine Biology 28, 87-94.

Soto, C., Hellebust, А. J., Hutchinson, T. C. \& 
SAWA, T. (1975a). Effect of naphthalene and aqueous crude oil extracts on the green flagellate Chlamydomonas angulosa. I. Growth. Canadian Journal of Microbiology 53, 109-117.

Soto, C., Hellebust, A. J., Hutchinson, T. C. $(1975 b)$. Effect of naphthalene and aqueous crude oil extracts on the green flagellate Chlamydomonas angulosa. II. Photosynthesis and the uptake and release of naphthalene. Canadian Journal of Microbiology 53, 118-126.

Treccani, V., Walker, N. \& Wiltshire, G. H. (1954). The metabolism of naphthalene by soil bacteria. Journal of General Microbiology 11, 341-348.

VAN BAALEN, C. (1962). Studies on marine bluegreen algae. Botanica marina 4, 129-139.

WALKer, N. \& WiltshiRe, G. H. (1953). The breakdown of naphthalene by a soil bacterium. Journal of General Microbiology 8, 273-276.

Winters, K., O'Donnell, R., Batterton, J. C. \& VAN BAALEN, C. (1976). Water soluble components of four fuel oils: chemical characterization and effects on growth of microalgae. Marine Biology 36, 269-276. 